\title{
Fine granular area formation induced by localized shear strain accumulation under very high cycle fatigue
}

\author{
Huan-Jie Zhang ${ }^{1}$, Feng $\mathrm{Yu}^{2}$, Shu-Xin $\mathrm{Li}^{1}$, and En-Guang $\mathrm{He}^{1}$ \\ ${ }^{1}$ Affiliation not available \\ ${ }^{2}$ Ningbo University
}

January 18, 2021

\begin{abstract}
A new perspective of localized shear strain accumulation was proposed to elucidate the formation mechanism of fine granular area (FGA) generated in a high strength steel under very-high-cycle fatigue (VHCF). On the one hand, experiments of VHCF under the negative stress ratio of -1 was carried out, and the microstructure of FGA was found and characterized by using Scanning Electron Microscope, Transmission Electron Microscopy, and Transmission Kikuchi Diffraction. The results show that the FGA consists of high-density dislocations, sub-grains, and fine grains with high angle grain boundaries. On the other hand, the evolution of shear strain and fatigue damage at the vicinity of an inclusion was modelled by using crystal plasticity finite element method at both positive and negative stress ratios. The results show that although the overall strain in VHCF is negligible, significant shear strain is accumulated at the vicinity of the inclusion. Such a large local strain is the driving force for the formation of FGA. The results also suggest that with the accumulation of shear strain and damage, the positive stress ratio is gradually evolved into negative. This may explain why FGA has also been reported at positive stress ratios in some literatures.
\end{abstract}

\section{Hosted file}

Manuscript -VHCF2.pdf available at https://authorea.com/users/390053/articles/504490-finegranular-area-formation-induced-by-localized-shear-strain-accumulation-under-very-highcycle-fatigue 